\title{
EL VIÑEDO EN ESPALDERA: NUEVA REALIDAD EN LOS PAISAJES VITIVINÍCOLAS DE CASTILLA-LA MANCHA
}

\author{
Ángel Raúl Ruiz Pulpón \\ Departamento de Geografía y Ordenación del Territorio. Universidad de Castilla-La Mancha \\ Angelraul.ruiz@uclm.es
}

\section{RESUMEN}

Los programas de reconversión y de reestructuración definidos en los últimos Reglamentos de la Organización Común del Mercado Vitivinícola, han contribuido a la modernización del sector a partir de la introducción de nuevas tipologías de viñedo que han mejorado ostensiblemente la rentabilidad en las explotaciones. El viñedo en espaldera es la consecuencia paisajística más relevante de este proceso, cuya expansión está originando notables repercusiones territoriales en Castilla-La Mancha, región que lidera la superficie y la producción nacional.

Palabras clave: Castilla-La Mancha, Organización Común del Mercado, programas de reconversión y reestructuración, viñedo en espaldera.

\section{ABSTRACT}

Vineyard Restructuring and Conversion Plans defined in the last Regulations of the Common Organization of the wine market, have contributed to the modernization of the sector from the introduction of new types of vineyard that have improved the profitability of farms. Trellis vineyard is the most important landscape result of these precepts, whose expansion is causing significant territorial impact in Castilla - La Mancha, region that leads the surface and the national production.

Key words: Castilla-La Mancha, Common Organization of the Market, restructuring programs, trellis vineyard.

Fecha de recepción: febrero 2012.

Fecha de aceptación: octubre 2012. 


\section{INTRODUCCIÓN}

El viñedo constituye uno de los aprovechamientos agrarios más importantes de CastillaLa Mancha, al contabilizar cerca de 467.960 hectáreas de extensión en 2010 (el 46,7\% de la superficie de viñedo nacional), según el Anuario de Estadística Agraria del mismo año. Las más de 700 industrias agroalimentarias que están relacionadas con la producción vitivinícola ponen de manifiesto, además, la importante fortaleza económica del sector. A lo largo de los últimos veinte años, las explotaciones y el tejido agroindustrial están viviendo un intenso proceso de modernización favorecido por la aprobación de las últimas Organizaciones Comunes del Mercado Vitivinícola (Reglamentos 1493/1999 y 479/2008) que abogan por la mejora de la competitividad de los vinos europeos en los mercados internacionales.

El proceso de modernización está basado no sólo en la mejora agronómica del cultivo, ya sea a partir de la renovación varietal, el ascenso de las superficies regadas y las nuevas tipologías de viñedo, sino también, en la apuesta por la innovación y por la calidad de las bodegas y de las Denominaciones de Origen. Tanto unas como otras han aumentando considerablemente las actividades dedicadas a la comercialización, generalizando los procesos de crianza, de embotellado y de exportación, que hasta la década de los años noventa han sido poco usuales (Arroyo, 1993). Consideramos que, al igual que ha acontecido en otras regiones españolas (Aparicio et al., 2008; Camacho et al., 2005; Castelló et al., 2010; Molleví, 2004; Morales, 2005; Piqueras, 1998), Castilla-La Mancha también ha efectuado su transición hacia un sistema productivo de calidad basado en la movilización de los recursos internos del territorio hacia la innovación, cuestión abordada desde diversos enfoques económicos ${ }^{1}$ (Peña, 2006; Aparicio et al., 2003; Castelló et al., 2010).

Uno de los instrumentos utilizados por la Administración para completar esta transición y regular el potencial vitivinícola han sido los programas de mejora y de acondicionamiento agronómico, más comúnmente conocidos como programas de reconversión y de reestructuración varietal. Las consecuencias en el paisaje han sido notables desde su puesta en marcha en el año 2000, al favorecer el riego de las explotaciones y al incentivar la implantación de un viñedo en espaldera que optimiza ostensiblemente las labores de mecanización.

El objetivo de este artículo es efectuar un primer balance del alcance territorial de esta medida comprendida dentro de los programas de reconversión y de reestructuración del viñedo. En especial, de la trascendencia territorial que el viñedo en espaldera ha alcanzado en las principales zonas productoras de la región. Las repercusiones territoriales pueden abordarse desde el punto de vista de la relación establecida con la industria agroalimentaria y las zonas de tradición vitivinícola, y de una forma más particular, con las consecuencias ambientales derivadas del empleo de recursos hídricos. El análisis de este tipo de consecuen-

1 La Teoría del Entorno o Medio Innovador (Aydalot, 1986) vincula la capacidad innovadora de las empresas con su entorno social, donde la capacidad de innovación depende de variables internas a los propios territorios, que proporcionan los activos que las empresas no pueden procurarse por sí solas, debido a su pequeño tamaño o la naturaleza pública y colectiva de los mismos (materias primas, servicios avanzados, etc....) (Alonso et al., 2008). En cambio, la Teoría de las Convenciones reúne los criterios que determinan las decisiones de los productores y los consumidores en torno a la calidad; similar significado tiene la Teoría de los Mundos de Producción que entiende el cambio desde el punto de vista de la combinación de tecnologías, de mercados y de estilos de utilización de los recursos (Castelló et al., 2010). 
cias puede ser fundamental cuando se está abogando, desde diferentes estamentos, por una mayor integración de las políticas sectoriales que intervienen sobre el territorio.

\subsection{Metodología y fuentes}

Las repercusiones territoriales se analizan desde el punto de vista de las dinámicas ambientales, sociales y económicas generadas. Ambientalmente, partimos de la generalización de los riegos de apoyo que garantizan la viabilidad agronómica de las explotaciones, aunque somos conscientes de la existencia de viñedos en espaldera en secano, especialmente relevantes en zonas como la D.O. Méntrida. Si tenemos en cuenta que la espaldera era prácticamente inexistente en los paisajes agrarios diez años antes, advertimos cómo se origina una nueva demanda de agua en una región caracterizada por la aridez y por las limitaciones de su potencial hídrico. Para calcular el consumo de las espalderas y otros usos agrarios contamos con las estimaciones propuestas en el Anexo V de la Orden de 25 de marzo de febrero de 2003 de la Junta de Comunidades que regulaba la concesión de ayudas para el ahorro de agua en los acuíferos sobreexplotados de Castilla-La Mancha, que establecía un consumo medio de $2.000 \mathrm{~m}^{3}$ por hectárea y año para el viñedo en espaldera (DOCM, 2003). Obviamente, esta cifra es orientativa, ya que el gasto real depende de otros factores como la actitud del agricultor y el volumen de precipitaciones anual.

Desde un punto de vista social y económico, es necesario vincular la distribución de la espaldera con las zonas tradicionales de producción y el tejido productivo. En este apartado se abordarán las dinámicas de los usos de suelo desde 1999 hasta la actualidad, para concretar si el crecimiento de las espalderas se ha efectuado a favor o en detrimento de los cultivos mediterráneos y para evaluar el nuevo consumo de agua generado. En segundo lugar, y teniendo en cuenta las empresas que participan en los procesos de transformación y de distribución en el sector, se calculará un índice $\mathrm{Z}$ de concentración de industrias vitivinícolas que nos servirá para determinar, una vez obtenidos los porcentajes de superficie de espaldera respecto a los totales de viñedo municipales, el significado de este nuevo aprovechamiento en las zonas vitícolas tradicionales.

Los principales indicadores utilizados han sido los del Registro Vitícola para el año 2010 que elabora la Dirección General de Producción Agropecuaria de Castilla-La Mancha. El Registro es un inventario acorde al artículo 8 de la Ley de la Viña y el Vino de Castilla-La Mancha que responde a la necesidad, según lo establecido en el artículo 108 del Reglamento (CE) $n^{\circ} 479 / 2008$, de que los estados miembros elaboren un registro sobre el potencial productivo vitivinícola. De forma completa recoge toda la información sobre la estructura y la evolución de las explotaciones vitícolas, las características agronómicas de cada plantación, y la identidad de los productores, con el objeto de conocer en todo momento la situación real y el potencial productivo de la viticultura regional. El archivo que hemos utilizado constituye un apartado de este registro, mostrando la superficie y las parcelas de espalderas por término municipal. Puede considerarse como una fuente de aceptable fiabilidad al garantizar la inscripción de todos los viticultores, aunque sería recomendable su contraste con trabajos de fotointerpretación.

Otras fuentes empleadas han sido las Superficies ocupadas por cultivos agrícolas (SOCAS) o Fichas 1-T de la Consejería de Agricultura y Desarrollo Rural de la Junta de Comunidades de Castilla-La Mancha para el año 2009, ante la falta de actualización de las de 2010 durante la elaboración de este trabajo. Entre sus ventajas destacan la profundidad tem- 
poral, ya que se vienen realizando desde la década de los setenta del siglo $\mathrm{XX}$, mientras que entre los inconvenientes resaltamos la falta de actualización de los indicadores pertenecientes a los aprovechamientos generales y los posibles errores en la obtención de datos (Pillet, 2001:55). En este caso, la limitación más importante radica en la ausencia de una variable de información relativa al viñedo en espaldera, suponiendo que esas superficies se contabilicen como de viñedo de uva para vino en la modalidad de regadío; por tanto, a la hora de calcular los consumos hídricos, se ha optado por contabilizar el viñedo en espaldera como de regadío a todos los efectos, sin tener la plena certeza de que esta fuente las recoja de forma parcial o total, y también, porque lográbamos un cálculo de consumo demasiado elevado al computar las espalderas de forma separada.

Por último, la misma Consejería publica también el Registro de industrias agroalimentarias de Castilla-La Mancha, catálogo que incorpora todas las empresas agroalimentarias por sector y por municipio, y las Cantidades percibidas por municipio de los Planes de Reconversión y Reestructuración donde figuran, de forma anual, las cantidades aprobadas por beneficiario a escala municipal, no significando necesariamente que el beneficiario haya ejecutado o llevado a cabo la transformación final.

\section{LAS MEDIDAS DE REGULACIÓN DEL POTENCIAL PRODUCTIVO EN LAS ÚLTIMAS ORGA- NIZACIONES COMUNES DEL MERCADO VITIVINÍCOLA}

La regulación del mercado vitivinícola europeo ha estado definida durante muchos años por la restricción y por la marginación. Nos referimos a la generalización de mecanismos como la destilación obligatoria con precios de castigo o el arranque subvencionado para combatir los excedentes a lo largo de la década de los años ochenta (Olmeda et al., 2003); y a la omisión, dentro de la trascendental Reforma MacSharry de 1992, de los cultivos mediterráneos en el sistema de pagos compensatorios fijados para los productos continentales -cereales, oleaginosas y proteaginosas-, agravando las diferencias existentes entre las agriculturas del norte y del sur de Europa. La falta de acuerdo de los países productores motivó el fracaso de la Organización Común de Mercado (OCM) prevista en 1994, aplazándola para el siguiente periodo financiero. No obstante, y a pesar de esta decepción, se asentaron las bases para la implantación de nuevas estrategias comerciales que se reflejaron en el Documento de reflexión sobre la evolución y el futuro de la política vitivinícola de 1993 que, de forma aún incipiente, abogaba por una mejor adecuación de la producción a los mercados a partir de la promoción de una viticultura de calidad (Salinas, 1998).

No será hasta la publicación del Reglamento 1493/1999 que aprobaba la Reforma de la OCM del vino cuando este tipo de iniciativas tengan una mayor relevancia, al proponer la adecuación del potencial vitivinícola de aquellas regiones con serios problemas de sobreproducción, como Castilla-La Mancha, región donde las experiencias relacionadas con la calidad y con la comercialización se encontraban aún en una fase inicial. Los problemas originados por los excedentes y la falta de competitividad de los vinos europeos en unos mercados internacionales cada vez más restringidos fueron asuntos clave de la Comunicación de la Comisión al Consejo y al Parlamento Europeo-COM (2006)319 final-de 22 de junio de 2006 que proponía una profunda Reforma de la Organización Común del Mercado Vitícola. Entre sus disposiciones, figuraba el establecimiento de medidas relacionadas con la regula- 
ción del potencial productivo y de apoyo a los mercados, entre las que sobresalían la fijación de una prima por arranque de viñedo en regiones con problemas de sobreproducción, el cuestionamiento de la prohibición de realizar nuevas plantaciones, la prórroga de los programas de reconversión y de reestructuración, y la futura supresión de las ayudas a la destilación y al almacenamiento privado por propiciar, según la Comisión, excedentes invendibles.

Estas medidas, implementadas y actualizadas en la actual OCM del vino (Reglamento 479/2008 de 29 de abril), han ocasionado una importante controversia en Castilla-La Mancha, y en especial, las dedicadas al arranque del viñedo y a la eliminación de las medidas de apoyo a los mercados. Respecto al arranque, estimado en un principio en 400.000 hectáreas y luego rebajado a 175.000, diversos actores sociales manifestaron las significativas consecuencias ambientales y sociales que se podrían derivar, destacando la aceleración de los procesos de desertización y de erosión (Bello et al., 1996:78); y el posible riesgo de desmantelamiento de zonas productoras tradicionales.

Respecto a la supresión de las medidas de apoyo a los mercados, concretamente de las ayudas a la destilación, al almacenamiento privado, y a las restituciones a la exportación, se ha convertido en el dictamen que mayor rechazo ha suscitado en la región, ya que el tejido productivo ha contado tradicionalmente con estas ayudas como fuente de financiación. Diversas plataformas de agricultores, cooperativas y sindicatos apostaron por la supresión de los fondos que se detraían del presupuesto de la OCM del vino para las políticas de desarrollo rural $^{2}$, denunciando, además, que la retirada de las medidas de apoyo contribuiría a abaratar aún más el precio de la uva, ante la posibilidad de que los industriales ya descontaran esta supresión de subsidios del precio final. Otras actuaciones, como la necesidad de seguir prorrogando los programas de reconversión y de reestructuración fijados desde la Reforma de 1999 han gozado, en general, del beneplácito de las administraciones y del sector vitivinícola.

\subsection{Los Programas de Reconversión y Reestructuración Varietal}

Los programas de reconversión y de reestructuración del viñedo fueron aprobados en el capítulo III del mencionado Reglamento 1493/1999. Se establecían en aquellas regiones donde la producción no se ajustaba a la demanda mediante una serie de acciones que contemplaban la reconversión varietal, la reimplantación de viñedos, y las mejoras en las técnicas de gestión.

Para asegurar un mejor seguimiento y planificación de estas medidas se encomendó a los estados miembros la responsabilidad de su ejecución (artículo 12), que en el caso español, se desarrolló con la aprobación del Real Decreto 1472/2000 que regulaba estas funciones y otras disposiciones emanadas del Reglamento europeo. En el capítulo V se hacía referencia a los programas de reconversión y reestructuración, anunciando las incompatibilidades, los plazos, los requisitos, los criterios de prioridad, y la modalidad de las ayudas. En todo caso, la presentación de solicitudes se debía hacer ante la Comunidad Autónoma pertinente y siempre velando por el no incremento del potencial productivo de la superficie afectada por

2 Colectivos como el Sindicato ASAJA, la «Plataforma por el agua y la viña de Castilla-La Mancha» y la Asociación «Salvemos el Campo». 
los mismos. Tres días después, mediante la Orden de 8 de agosto de 2000 de la Consejería de Agricultura y Medio Ambiente, se reguló la presentación y la concesión de ayudas a los planes de reconversión y de reestructuración del viñedo en Castilla-La Mancha, estableciendo ayudas a la reconversión varietal, entendidas como aquellas que se dedicaban al cambio de variedad de una parcela de viña mediante sobreinjerto y sin posibilidad de incrementar el número de cepas en la parcela; ayudas a la reestructuración, concebidas como aquellas intervenciones conducentes a la sustitución de parcelas de vid por la plantación de otra, en superficies equivalentes, y que contribuyeran a una mejora varietal o del sistema de cultivo; y por último, ayudas a la transformación en espalderas, que comprendía las operaciones y el material necesario para elevar una viña mediante un sistema de conducción apoyado en espaldera que permitiera una correcta mecanización, principalmente de las labores de poda y de vendimia (Ruiz, 2010: 18).

Las operaciones subvencionables estaban vinculadas con los costes de arranque, despedregado, preparación del suelo, nivelación, plantación, desinfección, y protección de plantas jóvenes y espalderas, estas últimas atendiendo a los costes de los materiales derivados de la transformación, estimados en 3.649 euros/ha. El límite del subsidio no podía sobrepasar el $75 \%$ del total de la inversión, si se trataba de proyectos colectivos, y del 63,75\% si se trataba de proyectos individuales. En todo caso, para determinar el importe de la ayuda era necesaria la medición de la superficie para obtener la superficie vitícola financiable. También se establecía una compensación por pérdida de ingresos estimada en 237 euros por hectárea, financiable sólo a un año cuando la operación comprendía la transformación en espaldera.

Desde el año 2000, la acogida al Programa ha sido un éxito tras contemplar las cantidades aprobadas y el número de beneficiarios (Tabla 1). En las tres primeras campañas ya se había cubierto el 71,3\% de las cerca de 100.000 ha que se estimaron como objetivo de reconversión en un plazo no superior a ocho años (Olmeda et al., 2003: 118). Desde 2003 hasta la actualidad se ha invertido una media anual de 65,5 millones de euros con un montante final de 458,7 millones de euros y más de 19.000 viticultores acogidos entre 2003 y 2009. En la evolución podemos contemplar una paulatina reducción de las cantidades a partir de 2006, circunstancia que habría que relacionar con la puesta en marcha de un nuevo periodo financiero (2007-2013).

Tabla 1

CANTIDADES OTORGADAS POR LOS PROGRAMAS DE RECONVERSIÓN Y REESTRUCTURACIÓN DEL VIÑEDO EN CASTILLA-LA MANCHA (2003-2009)

\begin{tabular}{|l|c|c|c|c|c|c|}
\hline & ALBACETE & CIUDAD REAL & CUENCA & $\begin{array}{c}\text { GUADALA- } \\
\text { JARA }\end{array}$ & TOLEDO & TOTAL \\
\hline 2003 & $19.821 .163 €$ & $26.183 .150 €$ & $12.717 .704 €$ & $23.842 €$ & $11.097 .343 €$ & $69.843 .202 €$ \\
\hline 2004 & $29.293 .927 €$ & $33.555 .446 €$ & $16.917 .763 €$ & $38.124 €$ & $14.667 .691 €$ & $94.472 .951 €$ \\
\hline 2005 & $24.849 .024 €$ & $22.283 .941 €$ & $15.494 .027 €$ & $19.227 €$ & $8.097 .640 €$ & $70.743 .859 €$ \\
\hline
\end{tabular}




\begin{tabular}{|l|c|c|c|c|c|c|}
\hline 2006 & $35.584 .195 €$ & $27.895 .763 €$ & $17.440 .598 €$ & $106.724 €$ & $11.104 .578 €$ & $92.131 .858 €$ \\
\hline 2007 & $24.789 .036 €$ & $17.059 .038 €$ & $13.483 .579 €$ & $422.787 €$ & $8.188 .773 €$ & $63.943 .213 €$ \\
\hline 2008 & $17.250 .166 €$ & $12.450 .665 €$ & $10.298 .056 €$ & $122.813 €$ & $6.672 .748 €$ & $46.794 .448 €$ \\
\hline 2009 & $4.651 .306 €$ & $8.728 .870 €$ & $3.008 .462 €$ & $14.382 €$ & $3.942 .636 €$ & $20.345 .656 €$ \\
\hline TOTAL & $\mathbf{1 5 6 . 2 3 8 . 8 1 7} €$ & $\mathbf{1 4 8 . 1 5 6 . 8 7 3} €$ & $\mathbf{8 9 . 3 6 0 . 1 8 9} €$ & $\mathbf{7 4 7 . 8 9 9} €$ & $\mathbf{6 3 . 7 7 1 . 4 0 9} €$ & $\mathbf{4 5 8 . 2 7 5 . 1 8 7} €$ \\
\hline
\end{tabular}

Fuente: Consejería de Agricultura y Medio Ambiente. Junta de Comunidades de Castilla-La Mancha. Elaboración propia.

A nivel provincial se constata la importancia de Albacete y de Ciudad Real, que reúnen el $67 \%$ del montante de las ayudas, donde los municipios asentados en la llanura manchega serán los máximos beneficiados. La consulta de los pagos nos demuestra que Villarrobledo, perteneciente a la provincia de Albacete, es la localidad que más dinero ha obtenido de media en el periodo 2003-2009, con cerca de 4 millones de euros anuales y unos 120 viticultores beneficiados al año, lo que significa que estamos hablando de un promedio cercano a los 34.000 euros por beneficiario. Le siguen los municipios de Tomelloso, Socuéllamos y Albacete capital, con unas cuantías cercanas a las 2 ó 3 millones de euros anuales y de 80 a 100 viticultores beneficiados anuales. Los subsidios por agricultor varían según el grado de fragmentación parcelaria, ya que Albacete, con una estructura de la propiedad y tamaño parcelario superior, presenta una media de 64.000 euros por perceptor, el doble que las cantidades de Tomelloso y otros municipios localizados en el centro de la región.

\section{REPERCUSIÓN EN LOS PAISAJES AGRARIOS DE CASTILLA-LA MANCHA: EL VIÑEDO EN ESPALDERA}

Estos programas han propiciado importantes cambios en los paisajes agrarios regionales, plasmados en la generalización de nuevas variedades y nuevas tipologías de viñedo. La diversificación productiva está relacionada con las variedades de uva que la propia Orden de la Consejería de Agricultura ha propuesto y recomendado en los últimos años. En el Informe publicado por la Junta de Comunidades de Castilla-La Mancha sobre el Sector vitivinícola de la región en 2007 (JCCM, 2007) se refleja este apoyo administrativo en el descenso interanual del 2,6\% de la variedad predominante, la blanca airén o manchega, desde el año 2000, en beneficio de tipologías tintas, que aumentaron un 3,1\% en el mismo periodo de tiempo. Entre todas ellas sobresale la cencibel o tempranillo, que era una variedad ya conocida en la región al utilizarse tradicionalmente en la elaboración de claretes o vinos tintos de poco color, y que ha pasado a constituir el 13\% de la superficie total de viñedo. También destacamos la aparición de la cabernet sauvignon, la garnacha tintorera y la syrah, con unas extensiones que no significarían más del $6 \%$ del total, junto a otras variedades tintas menos extendidas y también subvencionadas como la petit verdot, la mazuela, o la mencía. El descenso del resto de variedades se puede entender por su no consideración en los Anexos de la 
Orden, o bien porque han sido subsidiadas de forma parcial en algunas Denominaciones de Origen de Castilla-La Mancha.

\subsection{Nuevas tipologías de viñedo: el viñedo en espaldera}

La morfología de un viñedo en espaldera es totalmente distinta al de uno en vaso. A la mayor distancia entre las hileras, se le añade la utilización de postes, de alambres y de conducciones de riego por goteo que condicionan la disposición emparrada de los sarmientos, facilitando las labores de mecanización (Fig.1). Es ésta una de las principales ventajas porque se reducen los costes de producción derivados de la contratación de mano de obra en tiempos de recolección, tal y como tendremos ocasión de ver con posterioridad. La espaldera permite también otras ventajas agronómicas, como su posible cosecha nocturna para evitar la oxidación y mantener los aromas; la posibilidad de injertar más plantas en el mismo terreno (más de 500 cepas por hectárea); la mejor movilidad de la maquinaria entre los bancales, más anchos que los tradicionales, lo que impide que se afecten los sarmientos y se optimice la recogida del fruto; la mejor eficiencia de los tratamientos sanitarios; la disminución del riesgo de padecer ciertas enfermedades relacionadas con el exceso de humedad como el mildiú; la mejor maduración de la uva al recibir mayor cantidad de rayos solares, etc. (Sánchez et al., 1999).

Como principales inconvenientes podemos destacar la importante inversión inicial del agricultor en mano de obra para la colocación de los postes y de los alambres, las labores previas de despedregado, y la compra de la planta. La disponibilidad de agua también es un inconveniente, ya que se requieren entre 2.000 y $3.000 \mathrm{~m}^{3}$ de consumo medio por hectárea y año para su desarrollo, más cantidad que la de un viñedo en vaso. Desde el punto de vista agronómico, la espaldera es más sensible a los periodos secos y algunas variedades de uva, en especial las tintas, requieren de mayor humedad. Otros problemas estarían relacionados con la mejor selección de racimos que se efectúa en la vendimia manual, la menor defensa ante los vientos racheados, el impacto visual generado en el paisaje, y la reducción de empleo en las explotaciones.

\subsubsection{Distribución del viñedo en espaldera en Castilla-La Mancha}

De las cerca de 480.000 has de viñedo en producción de Castilla-La Mancha, el 18,1\% corresponden a viñedo en espaldera. Las 86.825 has registradas confirman la importancia estructural dentro de los usos agrarios regionales, al situarse por encima de la totalidad de los cultivos forrajeros, las leguminosas y los tubérculos de consumo humano. Por provincias (Tabla 2), Ciudad Real contribuye con más de un tercio de la superficie regional, seguida de Albacete y de Cuenca que albergarían en torno a una cuarta parte de las espalderas de Castilla-La Mancha (26,2\% y 22,5\% respectivamente). El protagonismo de Ciudad Real es debido a la existencia de una serie de municipios de importante tradición vitivinícola y considerable tamaño, que acaparan las más significativas extensiones regionales, ya que al analizar los resultados generales, de las diez localidades con mayor superficie, siete se sitúan en esta provincia, albergando poco más de 17.000 hectáreas (el 20\% del total). En cambio, en el resto de las provincias la extensión se encuentra más repartida, destacando el caso de Villarrobledo, que con 5.797 hectáreas contribuye al 25\% de la superficie provincial de Albacete. 


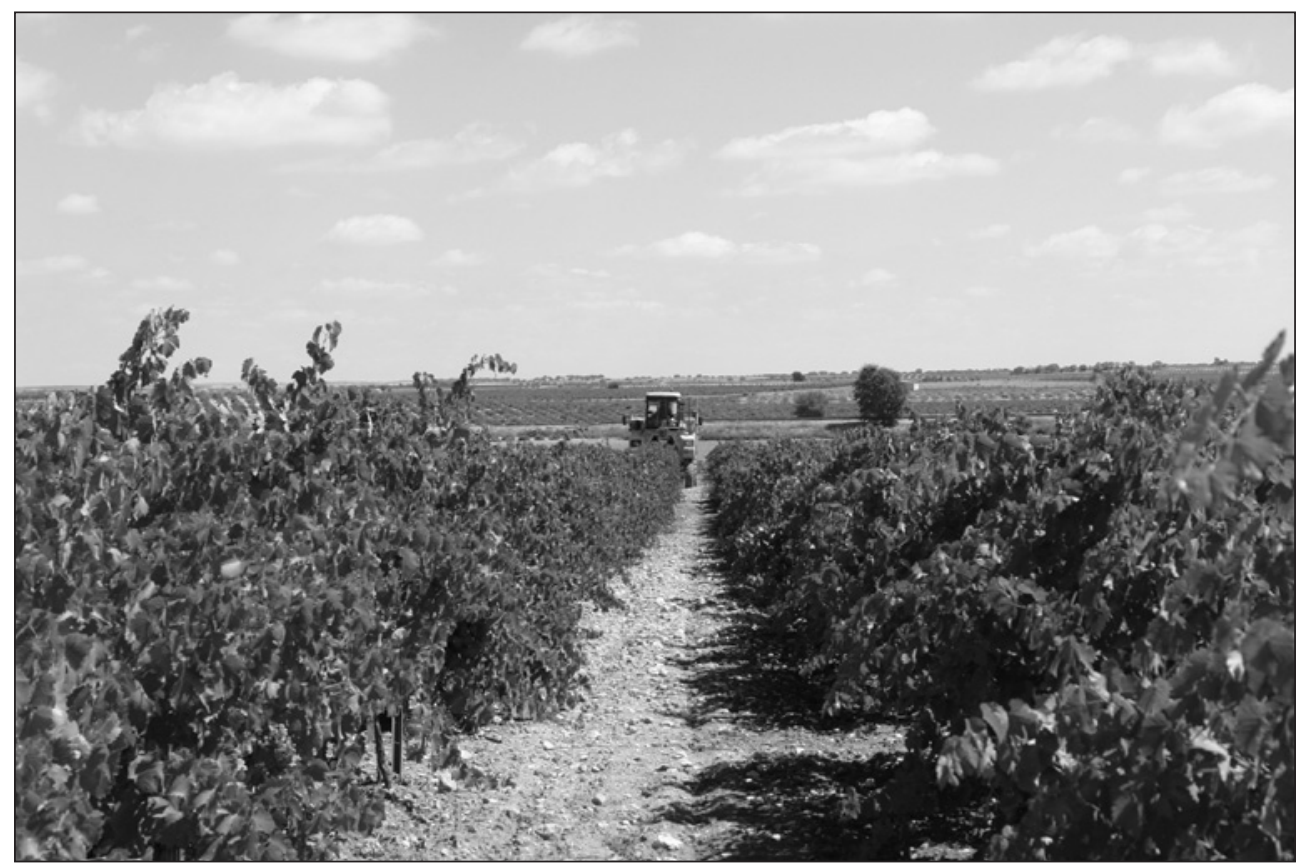

Foto: Ángel Raúl Ruiz Pulpón (septiembre de 2011). Municipio de Pedro Muñoz (Ciudad Real).

La relación respecto al total del viñedo provincial revela unos indicadores claramente distintos. En este caso, la provincia de Albacete ha transformado el 25,2\% del viñedo, frente a otras que se encuentran por debajo del promedio regional como Ciudad Real y Toledo. La explicación puede deberse al importante peso específico del viñedo en estas últimas (168.268 y 123.276 has respectivamente), mientras que Albacete, con tan sólo 90.000 has, cuenta con una estructura más diversificada y dinámica, como se deduce de que algunos municipios sin tradición vitivinícola acaparen hasta el 100\% de sus viñedos como espalderas.

La importante capacidad de adaptación del viñedo favorece su diseminación por gran parte de la región, exceptuando las zonas serranas y los lugares con suelos ácidos. Es la parte central, correspondiente a la Denominación de Origen «La Mancha», la que concentra la mayor parte de extensiones (un $61 \%$ del total), junto a otras zonas más periféricas localizadas en el extremo oriental (D.O. «La Manchuela»), suroriental (D.O. «Almansa»), noroccidental (D.O. «Méntrida») y meridional (D.O. «Valdepeñas»), aunque la espaldera se ha incorporado de una forma generalizada en la práctica totalidad de las D.O. regionales (Fig.2). En la D.O. La Mancha, el cultivo se adapta a los rigores del clima mediterráneo continental, apareciendo en llanuras de suelos profundos, de textura arcillosa-arenosa y ricos en calcio. Otras Denominaciones también han sabido adaptarse a las condiciones climáticas o bien atenuando sus efectos al encontrarse en terrenos cercanos a zonas serranas que actúan como barrera protectora (D.O. Méntrida), o bien porque se encuentran bajo la influencia de vientos húmedos 
Tabla 2

SUPERFICIE DE VIÑEDO EN ESPALDERA EN LAS PROVINCIAS DE CASTILLA-LA MANCHA (2010)

\begin{tabular}{|l|c|c|c|c|c|c|}
\hline & ALBACETE & $\begin{array}{l}\text { CIUDAD } \\
\text { REAL }\end{array}$ & CUENCA & GUADALAJARA & TOLEDO & CLM \\
\hline $\begin{array}{l}\text { Viñedo en } \\
\text { espaldera } \\
\text { (ha)* }\end{array}$ & $22.742,77$ & $29.938,20$ & $19.568,23$ & 128,32 & $14.448,22$ & $86.825,66$ \\
$\begin{array}{l}\text { \% total de } \\
\text { superficie de } \\
\text { espalderas* }\end{array}$ & $26,2 \%$ & $34,5 \%$ & $22,5 \%$ & $0,1 \%$ & $16,7 \%$ & $100 \%$ \\
\hline Parcelas* & 11.596 & 12.947 & 11.557 & 201 & 8.056 & 44.357 \\
\hline $\begin{array}{l}\text { Superficie } \\
\text { de viñedo } \\
\text { (has)** }\end{array}$ & 90.100 & 168.268 & 94.876 & 1.873 & 123.276 & 478.393 \\
\hline $\begin{array}{l}\text { Superficie de } \\
\text { espalderas } \\
\text { respecto } \\
\text { viñedo } \\
\text { provincial } \\
\text { (\%) }\end{array}$ & $25,2 \%$ & $17,8 \%$ & $20,6 \%$ & $6,8 \%$ & $11,7 \%$ & $18,1 \%$ \\
\hline $\begin{array}{l}\text { Superficie de } \\
\text { espalderas } \\
\text { respecto } \\
\text { superficie } \\
\text { cultivable } \\
\text { (\%) }\end{array}$ & $3,5 \%$ & $2,9 \%$ & $2,5 \%$ & $0,04 \%$ & $1,5 \%$ & $2,3 \%$ \\
\hline
\end{tabular}

Fuente:* Registro Vitícola (2010). Dirección General de Producción Agropecuaria. **Fichas 1-T del viñedo en producción (2009) Consejería de Agricultura de la Junta de Comunidades de Castilla-La Mancha. Elaboración propia.

procedentes del mediterráneo, posibilitando una mejora del proceso de maduración de la uva (D.O. Manchuela, Ribera del Júcar, Almansa). Además de los condicionantes topográficos y climáticos, la disponibilidad hídrica se configura como uno de los factores determinantes en la implantación de la espaldera, ya que las más importantes superficies coinciden con las principales zonas de riego subterráneo de Castilla-La Mancha.

Atendiendo a la Figura 2, las zonas centrales con mayores superficies coinciden con el acuífero de la Mancha Occidental, que reúne el $41 \%$ de las extensiones en una franja que a lo largo de 38 municipios recorre la parte nororiental de la provincia de Ciudad Real, el extremo suroccidental de la Cuenca y la noroccidental de Albacete. Más hacia el este se encuentra el acuífero de la Mancha Oriental (D.O. Manchuela), y en la parte septentrional, siguiendo la línea de separación entre las provincias de Toledo y Cuenca, encontramos los aprovechamientos ligados a las unidades acuíferas de la Sierra de Altomira y de Lillo-Quintanar corres- 
Figura 2

VIÑEDO EN ESPALDERA EN CASTILLA-LA MANCHA Y PRINCIPALES DENOMINACIONES DE ORIGEN

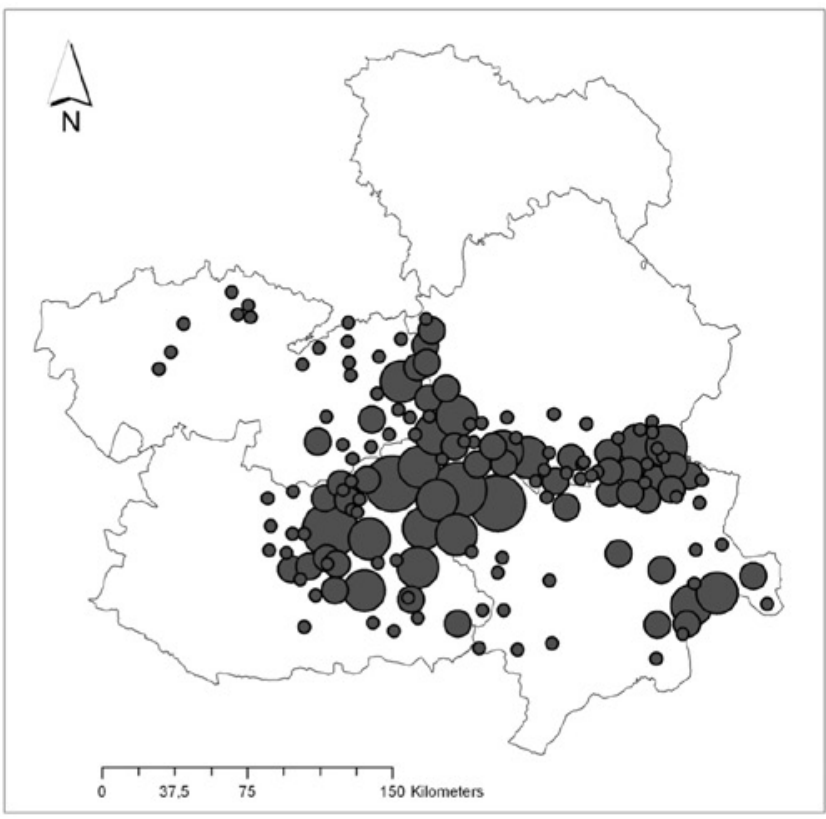

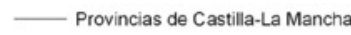

\section{Viñedo en espaldera}

- De 100 a 500 has

De 500 a 1.100 has

$\bigcirc$ De 1.100 a 2.200 has

Más de 2.200 has

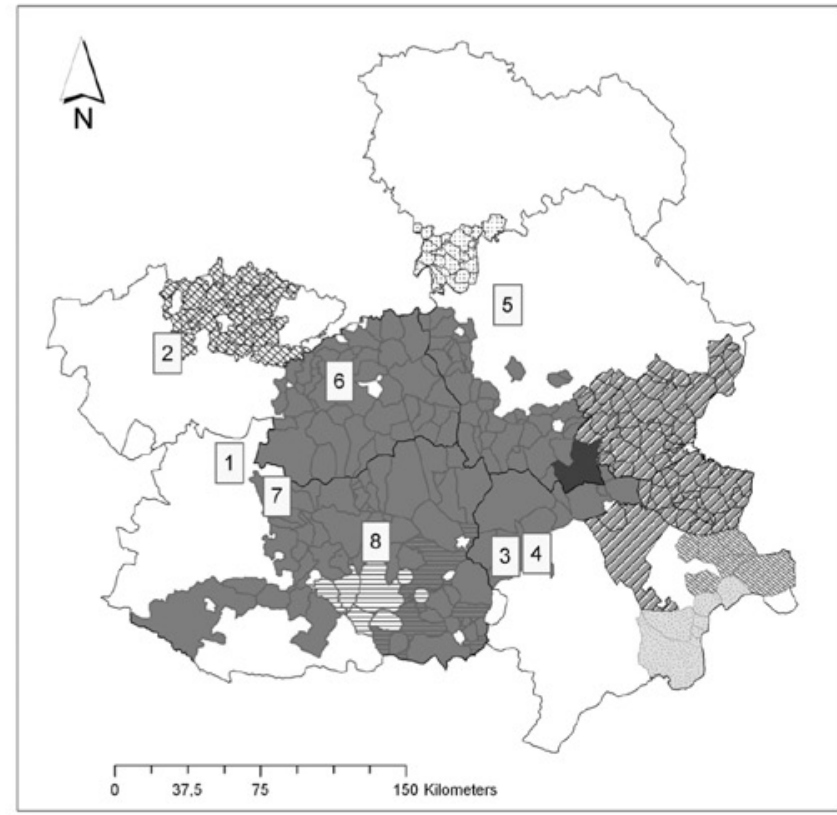

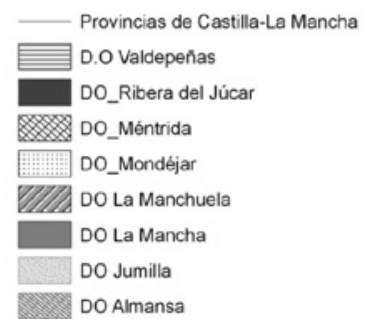

PAGOS VITIVINICOLAS CON D.O. PROPIA 1: Dehesa del Carrizal (Retuerta del Bullaque) 2: Dominio de Valdepusa (Malpica de Tajo) 3. Pago Gujoso (El Bonillo)

4: Finca Élez (El Bonillo)

5. Pago Calzadilla (Huete)

6. Campo de la Guardia (La Guardia)

7. Pago Florentino (Malagón)

8. Casa del Blanco (Manzanares)

Fuente: Registro Vitícola (2010) y Consejería de Agricultura y Desarrollo Rural de la Junta de Comunidades de Castilla-La Mancha. Elaboración propia. 
pondientes al acuífero terciario detrítico del norte de la Mancha (o acuífero 20). Otras áreas menos importantes se vinculan con otras unidades de menor consideración, como ocurre con el acuífero terciario detrítico de Toledo-Madrid o sistema acuífero 14 en la zona de la D.O. Méntrida.

A pesar de que este tipo de viñedo se puede cultivar en secano si contamos con la humedad suficiente, la aridez estival propia de los climas mediterráneos es un factor determinante en la incorporación de un riego de apoyo que permite completar la maduración y el engorde del fruto. El consumo hídrico puede variar según la variedad cultivada y la humedad del año hidrológico, aunque de forma general, las exigencias hídricas se estiman como moderadamente superiores a las tradicionales cepas en vaso. Según los consumos estimados por la administración, reflejados en distintos planes agroambientales puestos en marcha en los años noventa, el consumo medio estimado del viñedo en espaldera estaría en torno a los $2.000 \mathrm{~m}^{3}$ por hectárea y año, frente a los 1.500 del viñedo en vaso (DOCM, 2003).

La modalidad de riego predominante es la del goteo aéreo con o sin alambre, que resulta más eficiente que el riego por aspersión. Este último tiene una escasa relevancia en la actualidad al demostrarse la mayor eficiencia agronómica y económica de un riego localizado, que permite el ahorro al perderse menos agua por evaporación y también la reducción de los costes de producción asociados a la necesidad de mano de obra en épocas de riego, y a los derivados de los tratamientos fitosanitarios que combaten los posibles excesos de humedad de la aspersión.

La incorporación del regadío se puede entender, por tanto, como elemento indispensable del proceso de modernización de la viticultura de Castilla-La Mancha, tanto en viñedos en espaldera como en vaso; aunque los motivos de su introducción sean distintos. Si en los viñedos en espaldera la incorporación se ha efectuado para garantizar la viabilidad agronómica de las nuevas variedades más demandadas por los mercados, en los viñedos en vaso se ha venido realizando para incrementar la productividad y garantizar la viabilidad de muchas explotaciones, lo que ha contribuido al agravamiento del problema de los excedentes estructurales. El hecho de que la región pierda más de 160.000 has de viñedo en producción de secano entre 1999 y 2009 evidencia el éxito de la intensificación de este cultivo.

A pesar de que la posible generación de excedentes ya la contemplaba el Estatuto de la Vid y el Vino de 1970, en el proceso de intensificación ha jugado un papel esencial el levantamiento de la prohibición del riego de la vid en 1995, una vez que el Ministerio de Agricultura permitió que los viticultores gozaran de una situación más favorable y competitiva en el seno de la Unión Europea, ya que a diferencia de lo que ocurría en España, en Europa sí que estaba permitido el riego (CE, 1996: 233). El levantamiento de la prohibición también ayudó a que muchas explotaciones pudieran afrontar, de mejor manera, el periodo de sequía comprendido entre 1991 y 1995.

\subsection{Dinámicas territoriales: primeras valoraciones}

Hemos descubierto como la tradición vitícola y la presencia de recursos hídricos son factores que explican la distribución del viñedo en espaldera, factores que habría que relacionar con otras dinámicas que están interviniendo en el territorio y que no están exentas de conflictividad. 


\subsubsection{Dinámicas ambientales}

Las dinámicas ambientales están vinculadas con la generación de una nueva demanda hídrica en un territorio con importantes problemas de gestión del agua. Nos referimos a la conflictividad derivada de la sobreexplotación y de la contaminación de los acuíferos subterráneos que han puesto en serio peligro la conservación de espacios naturales de interés mundial, sin olvidar otras cuestiones sociales, económicas y políticas relativas a la puesta en funcionamiento del trasvase Tajo-Segura, las reivindicaciones sobre el empleo de recursos hídricos por parte de los sindicatos agrarios, y los riesgos que se ciernen sobre los abastecimientos urbanos.

En Castilla-La Mancha, el viñedo en espaldera consume 173,6 hm $\mathrm{hm}^{3}$ si estimamos un gasto medio de $2.000 \mathrm{~m}^{3}$ por hectárea y año y consideramos que el total de la extensión sea de regadío. Esta cifra significa que el viñedo en espaldera ya están utilizando más agua que los tubérculos, los cultivos industriales, los leguminosos y el olivar, siendo sólo superado por el riego de cereales, de hortalizas y del maíz, lo que refrendaría la importancia que ha alcanzado dentro de la estructura agraria (Tabla 3). Los resultados permiten afirmar que la incorporación de la espaldera no ha contribuido a incrementar el consumo de agua regional en las actividades agrarias durante la última década, debido a la pérdida de superficie de cultivos con altos requerimientos hídricos como la remolacha azucarera, la alfalfa y el maíz.

Desde 1999, el descenso de esta clase de cultivos ha supuesto un ahorro de $315 \mathrm{hm}^{3}$ a la región, para representar actualmente sólo el $27 \%$ del consumo regional. Las causas de este declive radican en el importante gasto unitario de agua que motivó el abandono de estos cultivos en zonas con menores posibilidades hídricas y en las disposiciones de sus respectivas organizaciones de mercado. Por ejemplo, la drástica bajada del precio del azúcar acordado en la OCM de 2004 determinó la desaparición de la remolacha, mientras que en el declive de la alfalfa han intervenido las continuas fluctuaciones de los precios, muy dependientes del comportamiento de la demanda del sector ganadero; la más que probable supresión de las ayudas a la transformación de forrajes en el año 2012 puede condicionar también la desaparición de este cultivo en Castilla-La Mancha. Las disposiciones de la Política Agraria Común también explican el éxito circunstancial de los cultivos oleaginosos y proteaginosos que recibieron pagos compensatorios durante la década de los noventa del siglo pasado, refiriéndonos especialmente a la colza, y a los linos oleaginoso y textil, que junto con la desprotección de los tubérculos de consumo humano determinan otro ahorro de $65 \mathrm{hm}^{3}$ en la última década.

A pesar de la disminución del consumo hídrico, observamos cómo el ritmo de propagación del viñedo en espaldera ha sido similar al acontecido en estos cultivos especulativos o sin tradición regional, poniendo de manifiesto la trascendencia de la toma de decisiones de la Política Agraria Común, que por regla general, se ha implementado de forma genérica y horizontal sin tener en cuenta las distintas especificidades de los territorios europeos.

\subsubsection{El viñedo en espaldera en el acuífero de la Mancha Occidental}

El acuífero de la Mancha Occidental se constituye como uno de esos territorios donde la integración de las políticas sectoriales es más apremiante, ya que desde 1994 ostenta 
Tabla 3

PRINCIPALES CULTIVOS Y CONSUMO HIDRICO EN CASTILLA-LA MANCHA

(1999-2009)

\begin{tabular}{|c|c|c|c|c|c|c|c|c|c|c|}
\hline & $\begin{array}{c}\text { Cereales } \\
\left(\mathbf{H m}^{3}\right)\end{array}$ & $\begin{array}{c}\text { Maíz } \\
\left(\mathbf{H m}^{3}\right)\end{array}$ & $\begin{array}{c}\text { Legumbres/ } \\
\text { industriales } \\
\left(\mathbf{H m}^{3}\right)\end{array}$ & $\begin{array}{c}\text { Tubérculos } \\
\left(\mathbf{H m}^{3}\right)\end{array}$ & $\begin{array}{c}\text { Remolacha } \\
\left(\mathbf{H m}^{3}\right)\end{array}$ & $\begin{array}{c}\text { Alfalfa } \\
\left(\mathbf{H m}^{3}\right)\end{array}$ & $\begin{array}{c}\text { Hortalizas } \\
\left(\mathbf{H m}^{3}\right)\end{array}$ & $\begin{array}{c}\text { Olivar } \\
\left(\mathbf{H m}^{3}\right)\end{array}$ & $\begin{array}{c}\text { Viñedo } \\
\left(\mathbf{H m}^{3}\right)\end{array}$ & $\begin{array}{c}\text { Total } \\
\left(\mathbf{H m}^{3}\right)\end{array}$ \\
\hline 1999 & 266,3 & 416,4 & 67,0 & 43,5 & 62,1 & 180,6 & 274,3 & 6,9 & 53,1 & 1.370 \\
\hline 2009 & 355,4 & 254,8 & 25,2 & 20,5 & 0,1 & 88,7 & 280,3 & 22,4 & $218,5^{*}$ & 1.212 \\
\hline
\end{tabular}

Fuente: Fichas 1-T. Consejería de Agricultura de la Junta de Comunidades de Castilla-La Mancha (1999-2009). Consumos (JCCM, 2003): Cereales $2.000 \mathrm{~m}^{3} / \mathrm{ha} /$ año; Maíz: $8.000 \mathrm{~m}^{3} /$ ha/año; Legumbres e industriales: $2.000 \mathrm{~m}^{3} /$ ha/año; Tubérculos: $5.500 \mathrm{~m}^{3} / \mathrm{ha} / \mathrm{año}$; Remolacha: $8.000 \mathrm{~m}^{3} / \mathrm{ha} / \mathrm{año}$; Alfalfa: $9.000 \mathrm{~m}^{3} / \mathrm{ha} / \mathrm{año}$; Hortalizas: $6.000 \mathrm{~m}^{3} /$ ha/año; Olivar: $1.500 \mathrm{~m}^{3} / \mathrm{ha} / \mathrm{año}$; Viñedo: $1.500 \mathrm{~m}^{3} / \mathrm{ha} / \mathrm{año}$.

*Se consideran $2.000 \mathrm{~m}^{3} / \mathrm{ha} / \mathrm{año}$ al introducir el viñedo en espaldera de 2010 .

la catalogación de acuífero definitivamente sobreexplotado por parte de la Confederación Hidrográfica del Guadiana. Actualmente, el acuífero alberga el $41 \%$ del viñedo regional en espaldera, con un consumo estimado de $70,8 \mathrm{hm}^{3}$, lo que supone un tercio del recurso disponible, estimado en 201,6 $\mathrm{hm}^{3}$ al año según el Borrador del Anteproyecto del Plan Hidrológico de cuenca del Guadiana. En un proceso similar al de la región, el significado de la espaldera en el agravamiento de los problemas de sobrexplotación del acuífero es relativo, ya que se han reducido sustancialmente los cultivos de alta necesidad hídrica que fueron precisamente los que motivaron la sobreexplotación en décadas anteriores, consiguiendo un ahorro estimado de unos $21,2 \mathrm{hm}^{3}$ en los municipios más importantes. El hecho de que el viñedo en espaldera consuma ya un tercio de los recursos disponibles, revela la escasa capacidad de coordinación entre las políticas agrarias y ambientales que actúan sobre el territorio, poniendo en riesgo distintas iniciativas que abogan por el cumplimiento de los plazos impuestos por la Directiva Marco del Agua de 2000 (Ruiz, 2012).

Sólo desde la integración de las políticas sectoriales se pueden implementar medidas que aboguen por la gestión racional de los recursos dentro del complejo marco normativo y concesional vigente tras la declaración de sobrexplotación, y que ha incrementado notablemente la conflictividad social en torno al uso del agua. Nos referimos a la obligatoriedad de contar con permiso administrativo para poder regar, a la prohibición de realización de nuevas captaciones, y al cumplimiento de Régimen de explotación anual que asigna los volúmenes máximos de agua a consumir por los agricultores. A todo ello se le añade que una parte considerable de los aprovechamientos regados de viñedo no tienen sus pozos reconocidos por el organismo de cuenca al no regular su situación en los plazos previstos (diciembre 1989), y que el riego de viñedo estuvo prohibido hasta 1995 por parte del Estatuto de la Vid y el Vino. Por tanto, existen una cantidad indeterminada de pozos 
ilegales que riegan viñedo y que se han ido incorporando a los programas de reconversión y de reestructuración. En este sentido, ningún punto de las Órdenes que han regulado estos programas hasta el año 2009 hacía referencia a la necesidad de contar con derechos concesionales (Ruiz, 2010b). Por tanto, resulta evidente que la administración regional no constató, en su momento, que las parcelas objeto de transformación contaban con derechos concedidos por la administración hidráulica, lo que supone un nuevo agravante en la falta de coordinación entre los organismos que gestionaban los recursos hídricos y las estructuras agrarias. Este desajuste se ha solucionado en la Orden de la Consejería que prorroga los programas en 2009 , requiriendo que las superficies a reconvertir cuenten con los consiguientes derechos reconocidos por la Confederación Hidrográfica o en su defecto, la solicitud de regularización.

Por tanto, la posesión de derechos de agua en acuíferos sobreexplotados es un elemento estratégico ya que permite que esos derechos puedan utilizarse para otros aprovechamientos agrarios. Municipios que no cuentan con la misma tradición, ni con la misma importancia de la viticultura dentro de sus estructuras agrarias como Daimiel, han visto crecer considerablemente sus superficies de viñedo en espaldera, mientras que los lugares con mayor raigambre del viñedo han visto limitada su transformación debido a que no accedieron de la misma forma al proceso de reconocimiento de derechos. Con el objetivo de regularizar parte de estos pozos que riegan vid y que se han incorporado a los programas de reconversión, el Plan Especial del Alto Guadiana ofrecía una regulación de los pozos que no accedieron al reconocimiento de derechos, dotando de concesiones gratuitas a aquellas explotaciones que cumplieran con unos determinados requisitos, como ser agricultor profesional y cultivar productos sociales. El resultado ha sido la regularización de unas 4.000 captaciones, según el Consorcio que gestionaba dicho Plan, lo que puede ser una cifra considerable teniendo en cuenta la difícil coyuntura económica.

\subsubsection{Dinámicas socioeconómicas}

A la hora de comprender la trascendencia del viñedo en espaldera en las zonas de producción tradicional, hemos relacionado la concentración empresarial vitivinícola, ponderada en un índice sintético Z que tiene en cuenta las Sociedades Agrarias de Transformación, las Sociedades Limitadas, Anónimas, Comunidades de Bienes, y las bodegas particulares, con el porcentaje del viñedo en espalderas respecto al viñedo total municipal (Fig.3). El resultado revela que los territorios que presentaban mayores superficies totales de espalderas, muestran en cambio, un significado de la misma poco relevante dentro de sus respectivos terrazgos municipales, debido al poder específico que aún tiene el viñedo en vaso. Por otra parte, comprobamos como existen otras zonas, distribuidas de forma periférica a las áreas de mayor concentración empresarial, que acaparan hasta el $100 \%$ de sus viñedos como espalderas, lo que certifica la dispersión territorial de los programas de reconversión al surgir nuevos viñedos prácticamente en todos los territorios donde ha sido posible. Un estudio detallado de estos lugares periféricos confirma la existencia de dos tipos de municipios:

- Municipios con posibilidades hídricas y con una estructura agraria diversificada que han incorporado los viñedos en espaldera como nuevo aprovechamiento. Se trata del com- 
portamiento más generalizado, siendo especialmente indicativo en el valle del río Tajo, en la parte occidental de la provincia de Cuenca, y en la parte centro-meridional de la de Albacete. En estas áreas se observa una tendencia común consistente en la reducción de cultivos leguminosos, tubérculos y maíz en favor de la espaldera.

- Municipios con escasas superficies municipales. Se trata de un conjunto que se asienta en zonas con relativas posibilidades hídricas e inmersas en contextos territoriales con manifiestas limitaciones físicas para la agricultura. En este sentido, destacamos las escasas superficies de la parte meridional de la provincia de Guadalajara, vinculadas a la zona de los embalses de Entrepeñas y Buendía, o los aprovechamientos de la parte noroccidental de la provincia de Ciudad Real, que concuerdan con suelos pliocuaternarios asociados a la zona regable del río Bullaque. Los condicionantes físicos singulares de estas zonas se constituyen como ventajas a la hora del reconocimiento de «vinos de pago» con Denominación de Origen propia, entendidos como una explotación que elabora vinos con unas características que lo distinguen respecto a otros de su entorno, y que cumplen con otros requisitos fijados por la administración, como el empleo de métodos de producción artesanal e innovadores, y el reconocimiento de la crítica especializada. Este es el caso de la Denominación de Origen propia «Dehesa del Carrizal» en el municipio de Retuerta del Bullaque (parte noroccidental de la provincia de Ciudad Real), finca que representa, por sí sola, el $50 \%$ de la superficie municipal de espalderas.

Siguiendo con el análisis de los lugares periféricos a las zonas de concentración industrial, podemos advertir que apenas cuentan con tradición vitivinícola, planteándose la hipótesis de que su aparición se deba a otro tipo de dinámicas especulativas. A pesar de que en Castilla-La Mancha predominan los viticultores profesionales, podemos reconocer que también han proliferado otro tipo de agentes socio-económicos que se incorporaron a la vitivinicultura regional procedentes de otras ramas productivas, en especial, de la construcción, desde los años noventa del siglo XX (Piqueras, 2008). De este tipo de iniciativas han surgido bodegas particulares que elaboraban vinos a partir de viñedos propios, y que además podían ofrecer otras actividades complementarias relacionadas con el enoturismo, la hostelería, etc. La actual crisis económica y la consecuente pérdida de dividendos procedentes de la construcción, ha condicionado la inviabilidad y el cierre definitivo de muchas de estas bodegas en Castilla-La Mancha y en España, en un proceso conocido como el «pinchazo de la burbuja del vino», término asociado al pinchazo de la burbuja inmobiliaria (Calvache, 2010).

En los municipios de la parte central de la región, que presentan unos porcentajes entre el 5 y el $10 \%$, predominan los viticultores a título principal y directo, cuya motivación para iniciar la transformación ha sido bien distinta a los anteriores. En general, los programas de reconversión se han visto como una oportunidad de modernizar sus explotaciones, al mejorar las formas de mecanización, y al mismo tiempo, reducir los costes de producción en un sector castigado por el bajo nivel de sus precios. El alcance de esta reducción lo podemos determinar en la Tabla 4, que recoge los resultados de un estudio llevado a cabo por el Instituto de la Vid y el Vino de Castilla-La Mancha (IVICAM) en 2010, denominado «Costes de producción de la uva en Castilla-La Mancha», que estima los costes medios de producción de distintas variedades de vid, teniendo en cuenta si se cultivan en vaso o en espaldera, y si son de regadío o no. 
Figura 3

INDUSTRIAS VITIVINÍCOLAS Y PORCENTAJE DE VIÑEDO EN ESPALDERA RESPECTO AL TOTAL DEL VIÑEDO DEL MUNICIPIO EN CASTILLA-LAMANCHA
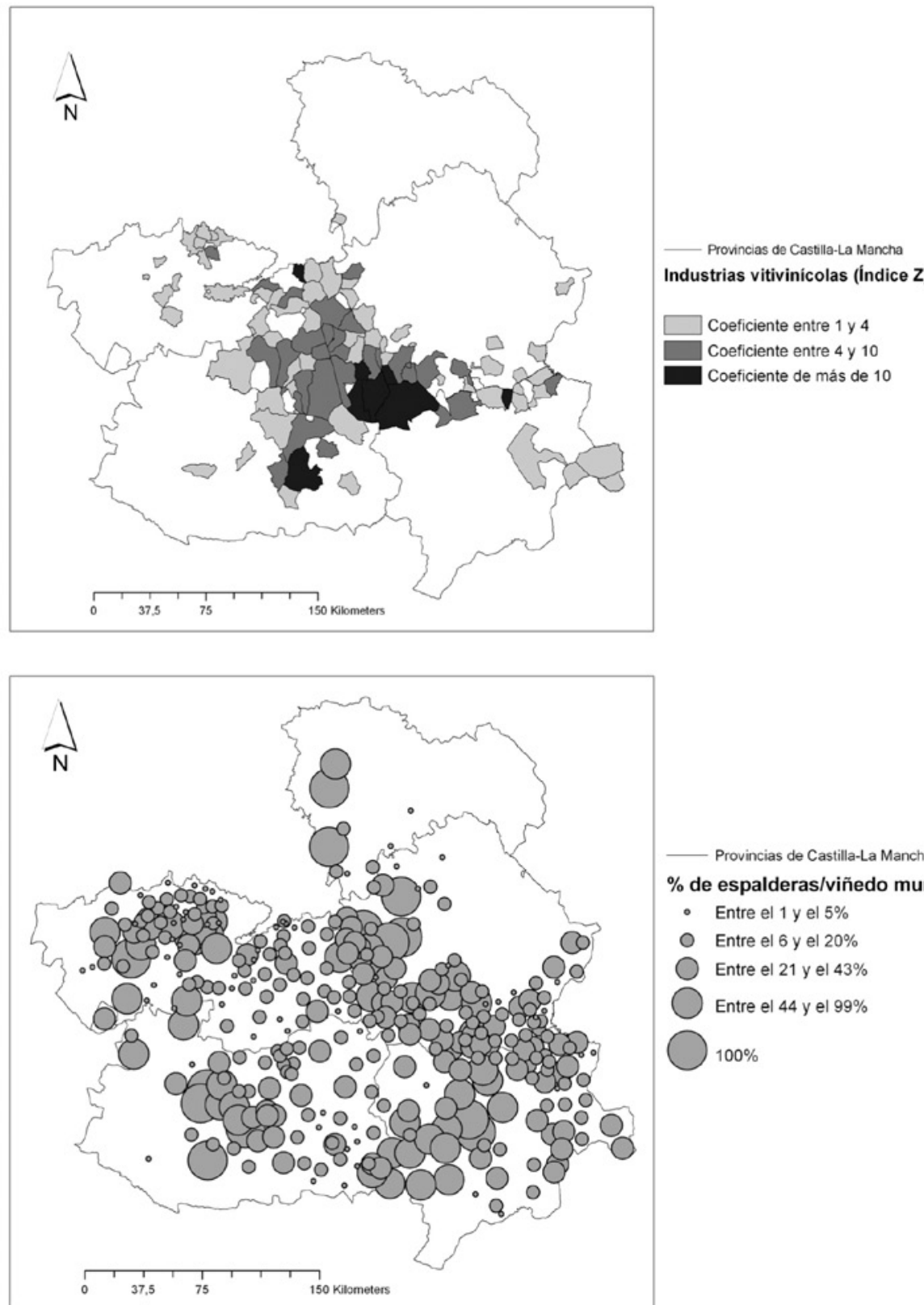

Provincias de Castilla-La Mancha

$\%$ de espalderas/viñedo municipal

- Entre el 1 y el $5 \%$

- Entre el 6 y el $20 \%$

Entre el 21 y el $43 \%$

Entre el 44 y el $99 \%$

$100 \%$

Fuente: Registro de Industrias Agroalimentarias de Castilla-La Mancha y Registro Vitícola. Consejería de Agricultura y Desarrollo Rural (total de viñedo municipal año 2009). Elaboración propia. 
Tabla 4

COSTES DE CULTIVO MEDIO POR AÑO Y HECTÁREA DE DIVERSAS VARIEDADES DE VID EN VASO Y EN ESPALDERA EN CASTILLA-LA MANCHA $(2010)$

\begin{tabular}{|c|c|c|c|c|c|}
\hline & \multicolumn{3}{|c|}{ AIRÉN } & \multicolumn{2}{|c|}{ CENCIBEL } \\
\hline & $\begin{array}{c}\text { Vaso } \\
(2,5 \times 2,5) \\
\text { secano }\end{array}$ & $\begin{array}{l}\text { Vaso }(2,5 \times 2,5) \\
\text { regadío }\end{array}$ & $\begin{array}{c}\text { Espaldera } \\
(\mathbf{3 x 1 , 5 )} \\
\text { regadío }\end{array}$ & $\begin{array}{c}\text { Vaso } \\
(2,5 \times 2,5) \\
\text { secano }\end{array}$ & $\begin{array}{c}\text { Espaldera } \\
(3 \times 1,5) \\
\text { regadío }\end{array}$ \\
\hline COSTES DIRECTOS $(€)$ & 912,8 & $2.089,8$ & $2.015,3$ & $1.039,8$ & $1.921,6$ \\
\hline $\begin{array}{l}\text { GASTOS GENERALES } \\
(€)\end{array}$ & 172,7 & 327,9 & 524,3 & 233,6 & 407,7 \\
\hline $\begin{array}{c}\text { GASTOS POR } \\
\text { HECTÁREA (€) }\end{array}$ & $1.085,6$ & $2.417,7$ & $2.539,7$ & $1.273,5$ & $2.329,3$ \\
\hline $\begin{array}{l}\text { RENDIMIENTO (KG/ } \\
\text { Ha) }\end{array}$ & 4.500 & 15.000 & 15.000 & 3.500 & 8.500 \\
\hline $\begin{array}{l}\text { GRADO MEDIO } \\
\text { ESTIMADO }\end{array}$ & $11,5^{\circ}$ & $10,5^{\circ}$ & $11,5^{\circ}$ & $13^{\circ}$ & $13^{\circ}$ \\
\hline $\begin{array}{l}\text { COSTE PRODUCCIÓN } \\
\text { KILO DE UVA }(€)\end{array}$ & 0,24 & 0,16 & 0,17 & 0,36 & 0,27 \\
\hline $\begin{array}{c}\text { COSTE PRODUCCIÓN } \\
\text { KILOGRADO }(€)\end{array}$ & 0,0208 & 0,0152 & 0,0147 & 0,0276 & 0,0207 \\
\hline $\begin{array}{c}\text { PRECIO KILOGRADO } \\
\text { D.O LA MANCHA } \\
2010(€)\end{array}$ & 0,0129 & 0,0129 & 0,0129 & 0,0147 & 0,0147 \\
\hline $\begin{array}{c}\text { PRECIO KILOGRADO } \\
\text { D.O VALDEPEÑAS } \\
2010(€)\end{array}$ & 0,0144 & 0,0144 & 0,0144 & 0,0178 & 0,0178 \\
\hline $\begin{array}{c}\text { PRECIO KILOGRADO } \\
\text { D.O. LA MANCHA } \\
\text { 2011(€) } \\
\end{array}$ & 0,0147 & 0,0147 & 0,0147 & 0,0159 & 0,0159 \\
\hline $\begin{array}{c}\text { PRECIO KILOGRADO } \\
\text { D.O VALDEPEÑAS } \\
2011(€) \\
\end{array}$ & 0,0153 & 0,0153 & 0,0153 & 0,0189 & 0,0189 \\
\hline
\end{tabular}

Fuente: Elaboración propia a partir de los datos facilitados por el IVICAM (Instituto de la Vid y el vino de CastillaLa Mancha). Precios: D.O. La Mancha y D.O. Valdepeñas.

Como observamos, los costes de producción por kilo de uva de las dos variedades predominantes en Castilla-La Mancha (airén y cencibel) son considerablemente menores si se cultivan en espaldera: en la variedad airén, el coste de producción en espaldera llega a ser hasta siete céntimos más barato que si se realiza en vaso y en secano $(0,17$ céntimos frente a 0,24 por kilo de uva producido), mientras que en la cencibel, el ahorro llega hasta los nueve céntimos $(0,27$ céntimos frente a 0,36 por kilo de uva producido). La estimación de unos costes más reducidos en espaldera se debe al mayor rendimiento por hectárea y a la mayor graduación obtenida, ya que como podemos comprobar, los gastos ocasionados por una hectárea de espaldera, una vez estimados costes directos y gastos generales, prácticamente duplican a los de los viñedos en vaso. En los costes directos se estiman los ocasionados por las operaciones y por los materiales empleados de un total de 20 indicadores, donde hay algunas labores que 
son exclusivas de la espaldera, como la prepoda mecánica, la elevación de vegetación, el despunte de sarmientos, la labores de mantenimiento del emparrado, y la vendimia mecánica. En los gastos generales, se agrupan la amortización de la explotación más intereses, los seguros de heladas y de pedrisco, los pagos de contribución y otros impuestos, y el interés capital circulante.

En la uva blanca airén el coste de las labores es bastante similar al comparar el riego en vaso y en espaldera, especialmente en cuestiones de estercolado, de abonado, de aplicación de herbicidas, y de costes de riego; mientras que es bastante desigual cuando los analizamos respecto a los viñedos en vaso y de secano, ya que prácticamente todas las labores de un viñedo en espaldera resultan más caras, excepto la recolección, al estimarse un coste de 288 euros/ha en viñas en vaso, y sólo 190 euros/ha por la vendimia mecánica. Otros estudios hablan de un coste final de recolección estimado en unos 0,035 euros por kilo en viñas en espaldera, una vez que se ha hecho frente al alquiler de una vendimiadora que puede oscilar en torno a los 300-350 euros por hora, frente a los 0,05 euros por kilo de una vendimia manual (Ruiz García y Bastida, 2006). El hecho de que la velocidad de cosecha sea de aproximadamente de dos hectáreas a la hora facilita, sin contar otras labores mecanizadas, que se duplique la superficie que puede atender una sola persona respecto a una cepa en vaso, consiguiendo, por tanto, un aumento de la rentabilidad estimado en un $25 \%$ dependiendo de la coyuntura de los mercados y de la variedad de uva que se cultive (Sánchez Rodríguez et $a l .$, 1999). En la variedad cencibel, la situación es similar, aunque existe una menor diferencia en los tratamientos fitosanitarios y en la aplicación de abonado. Respecto a los gastos generales, la espaldera muestra unos indicadores superiores en todos los ítems, sobre todo los que se vinculan con la amortización de las inversiones realizadas. Por tanto, la introducción de la espaldera puede plantearse también como una estrategia empresarial ante los problemas actuales del sector vitivinícola, sobre todo de las derivadas de los fluctuantes precios de la uva y de la conflictividad en la contratación de mano de obra.

El precio final de la uva se determina por el grado de azúcares que contiene, que es distinto cada año, y el rendimiento de la explotación. Según los cálculos efectuados en el estudio se obtiene un precio final de 0,0147 céntimos por kilogrado en variedad airén y en espaldera, y de 0,0207 en cencibel. Estos costes los hemos puesto en relación con los últimos precios determinados en las dos denominaciones de origen más importantes de Castilla-La Mancha: La Mancha y Valdepeñas. Los resultados evidencian que los precios actuales están ligeramente por debajo de los precios de producción, siendo sólo rentables en la variedad airén en 2011 en espaldera y en la D.O. Valdepeñas. Este juego de cifras debe estimarse como orientativo, ya que el coste de producción final de la cosecha varía según la producción, el grado alcoholímetro y al precio que resuelve cada cooperativa o Sociedad Agraria de Transformación a sus respectivos socios, además de que los gastos estimados en el informe pueden reducirse si algunas tareas las realiza directamente el agricultor. Desde el sindicato agrario ASAJA $^{3}$ se criticó duramente la fijación de estos precios, similares a los obtenidos en 1989, denunciando que la cosecha para el año 2011 ha sido sensiblemente inferior a la campaña anterior, que muchas bodegas estaban solucionando sus problemas de almacena-

3 La Tribuna de Albacete, 31-08-2011 
miento, y que se había experimentado un aumento de las exportaciones en los últimos años, especialmente a países como China y Rusia.

\section{CONSIDERACIONES FINALES}

El viñedo en espaldera se ha convertido en el elemento visual más perceptible del proceso de modernización del sector vitivinícola castellano-manchego, al introducir conjuntamente una renovación varietal y una optimización de la mecanización de las labores agrícolas que han favorecido la transición hacia un sistema productivo basado en la innovación, en la competitividad y en la calidad. Con una extensión cercana a las 90.000 has, se trata actualmente de un cultivo con una significativa representación y dispersión en Castilla-La Mancha, lo que ha contribuido al proceso de diversificación productiva de muchas zonas agrarias regionales, aunque son las áreas vitivinícolas tradicionales las que presentan las mayores extensiones dentro del predominante viñedo en vaso de variedad blanca airén o manchega.

La aparición de estas 90.000 has nuevas ha originado evidentes impactos territoriales. Sin cuestionar los avances experimentados en las explotaciones vitivinícolas para mejorar su rentabilidad y conseguir una mejor adecuación a los mercados, consideramos que la implantación de una Organización Común del Mercado del vino de forma horizontal en los distintos contextos territoriales europeos supone un factor de riesgo al no considerar, al menos en una fase inicial, las características y las debilidades de cada uno de estos territorios. Esta necesidad se hace más ineludible cuando hablamos de medidas con tanta trascendencia espacial como el arranque de viñedo y los programas de reconversión y de reestructuración del viñedo en una región con una importante tradición vitícola y con territorios con serios problemas de sostenibilidad. El arranque resulta claramente negativo al plantearse sobre una región donde la vid es parte integrante de los paisajes, generando perjuicios ambientales al fomentar la erosión y la desertización; y sociales, al prescindir de un tipo de viñedo tradicional que contribuye a la configuración de paisajes de indudable valor escénico y patrimonial. Respecto a los programas de reconversión, la expansión del viñedo en espaldera puede cuestionarse porque se ha realizado en territorios con importante conflictividad social y ambiental, como el acuífero de la Mancha Occidental, declarado definitivamente sobreexplotado desde 1994, y donde la espaldera ya contabiliza 35.400 has. En este lugar, resulta lógico pensar que la introducción de las nuevas variedades de viñedo y/o la mecanización en forma de espaldera se debería haber llevado de una forma más ordenada y prudente, en coordinación con el resto de administraciones, sobre todo la ambiental y la agraria, ya que la espaldera se ha convertido en un elemento más de presión sobre los mermados recursos hídricos del territorio, poniendo en riesgo postulados que apuestan por la gestión eficaz e inteligente de los recursos, como la Directiva Marco del Agua, y otras políticas propuestas a nivel específico por la Administración ambiental, como el Plan Especial del Alto Guadiana y el último Plan Hidrológico de Cuenca.

En definitiva, la integración de las políticas sectoriales que intervienen sobre el territorio es una de las más importantes tareas a emprender por parte de las Administraciones públicas, cuestión especialmente difícil cuando se trata de un recurso tan multifuncional y estratégico como el agua. 


\section{BIBLIOGRAFÍA}

ARROYO, F. (1993): «El impacto de las Denominaciones de Origen en la Modernización de la viticultura española: el caso de Castilla-La Mancha» en Medio siglo de cambios agrarios en España (Gil, A. y Morales, A. Eds.). Alicante. Diputación Provincial de Alicante, págs. 243-279.

APARICIO, L.J. et al. (2003): «Los espacios vitivinícolas en Castilla-León: la evolución hacia un sistema productivo de calidad», en Boletín de la Asociación de Geógrafos Españoles $\mathrm{n}^{\mathrm{o}} 35$, págs. 101-122.

ALONSO, L.J. et al. (2008): «La ribera del Duero, geografía de un medio innovador en torno a la viticultura», en Scripta Nova Revista electrónica de geografía y ciencias sociales, $\mathrm{n}^{\circ}$ 12, págs. 256-280.

AYDALOT, P. (1986): Milieux innovateurs en Europe. GREMI, París.

BELLO, A. et al. (1996): «Valores agroambientales de los viñedos de La Mancha y protección de cultivos» en La vid y el vino en Castilla-La Mancha (Salinas y otros, Eds) Albacete. Junta de Comunidades de Castilla-La Mancha, págs. 63-81.

CALVACHE, F. (2010): «La burbuja inmo-vinaria II» en Revista Baco Digital. Disponible en http://www.bacodigital.com/2010/02/03/vino-la-burbuja-inmo-vinaria-II-franciscocalvache/

CAMACHO, M.T.; PAEGELOW, M.; TULET, J-C. (2005): «L'évolution spatiale du vignoble andalou depuis l'entrée de l'Espagne dans l'ensemble européen», en Sud-ouest européenne : revue géographique des Pyrénées et du Sud-ouest n ${ }^{\circ} 20$, págs. 79-89.

CASTELLÓ, A. et al. (2010): «Los paisajes vitivinícolas en la economía rural aragonesa», en F. Leco et al. (Eds.), Actas del XV Coloquio de Geografía Rural de España, Cáceres.

CONSEJO DE ESTADO (1996): Memoria del año 1996. Madrid, Gobierno de España.

COMISIÓN DE LAS COMUNIDADES EUROPEAS (2006): Comunicación de la Comisión al Consejo y al Parlamento Europeo - COM (2006)319 final. Hacia un sector vitivinícola europeo sostenible. Bruselas, Comisión Europea.

CONFEDERACIÓN HIDROGRÁFICA DEL GUADIANA (2003): Plan Especial del Alto Guadiana. Badajoz, MIMAM.

DOCM (2003): Orden de la Consejería de Agricultura y Medio Ambiente, por la que se regula el procedimiento, tramitación y concesión de las ayudas para el ahorro de agua en los regadios de las zonas de Mancha Occidental y Campo de Montiel. Toledo, Junta de Comunidades de Castilla-La Mancha.

FERNÁNDEZ, J. (2010): «Las transformaciones del paisaje del viñedo en la denominación de origen Cigales», en F. Leco et al. (Eds.), Actas del XV Coloquio de Geografía Rural de España, Cáceres.

IGME (1985): Síntesis hidrogeológica de Castilla-La Mancha. Madrid, IGME.

IVICAM (2011): Informe sobre costes de producción de uva en Castilla-La Mancha. Tomelloso. Instituto de la Vid y el Vino de Castilla-La Mancha-Junta de Comunidades de Castilla-La Mancha.

JUNTA DE COMUNIDADES DE CASTILLA-LA MANCHA (2007): Análisis del sector vitivinícola de Castilla-La Mancha, en: http://pagina.jccm.es/agricul/cese/presentacion_espanol_CESE-NOV07.pps 
JUNTA DE COMUNIDADES DE C-LM (2012): Estrategia Regional del vino y los productos derivados de la uva de Castilla-La Mancha. Toledo, Junta de Comunidades de Castilla La-Mancha.

MOLLEVÍ, G. (2004): «Desarrollo de algunas comarcas de Cataluña gracias al potencial endógeno en el sector vitícola», en Boletín de la Asociación de Geógrafos Españoles n ${ }^{\circ}$ 38, págs. 261-271.

MORALES, A. (2001): «Reestructuración espacial y cualitativa reciente del viñedo de la región de Murcia», en Manero, M. (Coord.): Espacio natural y dinámicas territoriales: homenaje al Dr. Jesús García Fernández. Universidad de Valladolid, págs. 503-514.

OLMEDA, M. et al. (2003): El viñedo y el vino de Castilla-La Mancha. Colección Ciencia y tecnología 44. Cuenca, Ediciones de la Universidad de Castilla-La Mancha.

PEÑA, A.R. (2006): Las disparidades económicas intrarregionales en Andalucía. Tesis Doctoral. Servicio de publicaciones de la Universidad de Cádiz.

PILLET, F. (2001): La Mancha. Transformaciones de un espacio rural. Madrid, Celeste Ediciones, Colección Biblioteca Añil, 180 p.

PIQUERAS, J. (1998): «Cambios recientes en el sector vitivinícola valenciano. 1977-1997», en Cuadernos de Geografía nº 63, págs. 177-194.

PIQUERAS, J. (2008): «El sector vitícola español y la PAC 1986-2005: del optimismo a la crisis», en Araque, E. et al. (Eds.): Las agriculturas españolas y la Política Agraria Comunitaria: 20 años después. Baeza, UIA, págs. 307-324.

RUIZ GARCÍA, L. y BASTIDA, R. (2006): «Panorama actual de las vendimiadoras en España», en Vida Rural n 231, págs. 50-53.

RUIZ PULPÓN, A.R. (2010): «Evolución y consolidación del viñedo de regadío en La Mancha», en Boletín de la Asociación de Geógrafos Españoles n 52, págs. 5-26.

RUIZ PULPÓN, A.R. (2010b): «Conflictividad social en torno al viñedo de regadío en la cuenca alta del río Guadiana. Necesidad de regulación», en Leco et al. (Eds.), Actas del XV Coloquio de Geografía Rural de España, Cáceres.

RUIZ PULPÓN, A.R. (2012): «Gestión del agua e integración de políticas sectoriales. Balance y situación actual en el territorio del Alto Guadiana», en Documents d'Análisi Geográfica, Vol. 58/1, págs. 101-120.

SALINAS, A. (1998): «El marco europeo», en Montero, F. J. y Brasa, A. (Coords.), El viñedo en Castilla La Mancha ante el siglo XXI. El sector vitivinícola y el agua. Cuenca, Universidad de Castilla-La Mancha, págs. 271-285.

SÁNCHEZ RODRÍGUEZ et al. (1999): «Cultivo de la vid en espaldera», en Cuadernos de Divulgación, Gobierno de Canarias, 20 págs. 